\title{
Análise da Oficina Estratégias para o Ensino de Biologia Celular: fortalecendo a troca de experiências entre graduação e pós-graduação
}

\section{Analysis of the Office Strategies for the Teaching of Cell Biology: strengthening the exchange experience between graduation and post-graduation}

\author{
${ }^{1}$ Andreza Maciel Rocha andrezamaciel2@hotmail.com \\ ${ }^{1}$ Maria Izabel Gallão
}

\section{RESUMO}

Novas estratégias de ensino, utilizadas com o auxílio das modalidades didáticas, são muito importantes para a obtenção de melhor assimilação, compreensão, desenvolvimento do conteúdo por parte dos estudantes, instigando a buscar novas formas de aplicação do conteúdo aplicado em sala. Objetivo desse trabalho é analisar os resultados dos diálogos proporcionados pela realização de uma oficina sobre diferentes estratégias para uso no ensino de biologia celular, ministrada por alunos de pós-graduação para estudantes de graduação em Licenciatura em Ciências Biológicas. Foram aplicados questionários no último dia das oficinas. Com resultados, afirmamos que as diferentes estratégias para o ensino de biologia celular e a experiência proporcionada pela oficina foi positiva. Os estudantes participantes concordaram que o processo de ensino de assuntos relacionados ao estudo da célula pode vir a ser facilitado quando apresentado através de uma estratégia ou modalidade didática corretamente aplicada.

Palavras-chave: Modalidades Didáticas. Ensino de Ciências. Biologia Celular.

\begin{abstract}
New teaching strategies, used with the aid of didactic modalities, are very important for obtaining better assimilation, understanding, and development of content by students, instigating them to seek new ways of applying the content applied in the classroom. The objective of this work is to analyze the results of the dialogues provided by the realization of a workshop on different strategies for use in the teaching of cell biology, taught by graduate students for undergraduate students in Biological Sciences. Questionnaires were applied on the last day of the workshops. With results, we affirm that the different strategies for teaching cell biology and the experience provided by the workshop was positive. The participating students agreed that the process of teaching subjects related to the study of the cell can be facilitated when presented through a strategy or didactic modality correctly applied.
\end{abstract}

Keywords: Didactic Modalities. Science teaching. Cell biology.

1 Universidade Federal do Ceará 


\section{INTRODUÇÃO}

Ensinar biologia é, sem dúvidas, um desafio constante na rotina de todos os docentes responsáveis por ministrar os temas nessa área de ensino. Para Krasilchik (2011), a explanação dos conhecimentos biológicos pode, no ponto de vista do interesse dos estudantes, se configurar tanto entre as mais fascinantes, quanto o contrário. A autora atribuí tal dualidade a fatores como a composição do conteúdo programático e a forma no qual são ministrados, destacando que os assuntos devem "contribuir, também, para que o cidadão seja capaz de usar o que aprendeu ao tomar decisões de interesse individual e coletivo, no contexto [...] que leve em conta o papel do homem na biosfera" (KRASILCHIK, 2011, p. 13). Já Borges e Lima (2007, p. 166) observam que "o ensino de biologia se organiza ainda hoje de modo a privilegiar o estudo de conceitos, linguagem e metodologias desse campo do conhecimento, tornando as aprendizagens pouco eficientes". Assim, ainda conforme os autores, deve-se haver uma "reflexão profunda” sobre quais devem ser os conteúdos explanados nas aulas de biologia e suas metodologias correspondentes objetivando satisfazer as nossas necessidades contemporâneas (BORGES; LIMA, 2007, p. 166).

Dentre os assuntos nos quais se verificam a necessidade de atenção e reformulação de estratégias didáticas está a Biologia Celular. Justificativas para tal demanda são facilmente encontradas na literatura. Krasilchik (2011, p. 18, grifo do autor), por exemplo, já ressaltava a "tendência descritiva" dos programas para o ensino médio a partir dos anos 90, destacando a percentagem em que determinados conteúdos surgiam em currículos voltados para o ensino médio. Por sua vez, autores como Orlando et al. (2009, p. 2) recomendam a "elaboração de um material de apoio ao conteúdo presente nos livros texto", podendo este ser modelos didáticos, ao comentar que as temáticas de biologia que contemplam a Biologia Celular e Molecular no ensino médio serem conhecidos por apresentarem "conceitos bastante abstratos e trabalha[rem] com aspectos microscópicos” (ORLANDO et al., 2009, p. 2). Já Randi e Carvalho (2013, p. 81), dessa vez se referindo ao ensino superior, comentam que "ensinar biologia celular [...] não é uma tarefa fácil, especialmente porque a biologia celular apresenta uma série de conhecimentos abstratos”. Apesar dos últimos autores traçarem esse comentário perante ao âmbito acadêmico, podemos estendê-lo, com base na literatura, a realidade do ensino básico.

Diante destes aspectos, um dos pontos fundamentais para a otimização do processo de ensino e aprendizagem de determinados conteúdos passa pela seleção de quais modalidades deverão ser utilizadas em "atividades e experiências que melhor levem à consecução dos objetivos propostos” (KRASILCHIK, 2011, p. 79). Novas estratégias de ensino, utilizadas com o auxílio das modalidades didáticas, são muito importantes para a obtenção de melhor assimilação, compreensão, desenvolvimento do conteúdo por parte dos estudantes, instigando a buscar novas formas de aplicação do conteúdo aplicado em sala. Tais mudanças de perspectivas podem resultar numa substituição do ensino acumulativo e descontextualizado no qual a Biologia Celular está, em determinadas situações, imersa.

Dessa forma, o objetivo desse trabalho foi analisar os resultados proporcionados pela realização de uma oficina sobre diferentes estratégias para uso no ensino de biologia celular, ministrada por alunos de pós-graduação/professores de escolas públicas para estudantes de graduação em Licenciatura em Ciências Biológicas.

\section{METODOLOGIA}

A oficina "Estratégias para o Ensino de Biologia Celular" ocorreu durante a disciplina de Biologia I do Mestrado Profissional em Ensino de Ciências e Matemática (ENCIMA) da Universidade Federal do Ceará, o presente trabalho não foi submetido ao comitê de ética. Sua preparação se iniciou simultaneamente com as aulas, entre os meses de março a junho de 2017 e contou com a participação de oito alunos, também professores de escolas públicas, inscritos no eixo Biologia do programa. Esses mestrandos participaram da elaboração, organização e ministraram os conteúdos da oficina sob orientação e supervisão da professora da disciplina. As orientações e planejamentos foram distribuídos da seguinte forma: 
$1^{a}$ aula: Os alunos foram convidados a socializar sobre as experiências vividas na graduação em Ciências Biológicas e como professores de biologia. Na ocasião, também foi apresentada a proposta para a realização das oficinas sobre estratégias didáticas para o ensino de biologia celular.

$2^{a}$ aula: Definição das quatro estratégias da oficina - jogos didáticos, fanzines, TIC’s (Tecnologias da Informação e Comunicação) e sequências didáticas - da escolha da Respiração Celular como tema central e a elaboração de uma apostila a ser entregue para os participantes.

$3^{a}, 4^{a}$ e $5^{a}$ aulas: Apresentação teórica do tema Respiração Celular pela professora da disciplina. Foi dado continuidade ao levantamento teórico e organização da apostila.

$6^{a}$ aula: Correção dos capítulos da apostila e início da divulgação da oficina entre os estudantes de Ciências Biológicas.

$7^{a} e 8^{a}$ aulas: Elaboração dos questionários de avaliação e finalização dos capítulos da apostila e levantamento do material para uso nas oficinas.

$9^{a}$ aula: Pré-apresentação das oficinas para a professora da disciplina e demais participantes da turma.

$10^{a}$ e $11^{a}$ aulas: Realização das oficinas de jogos didáticos, fanzines, TIC’s e sequência didática, duas por dia, respectivamente.

Os questionários foram divididos em dois grupos: para os alunos da graduação avaliarem o desenvolvimento da oficina e para os professores avaliarem a satisfação do desenvolvimento da oficina. Dezenove questionários, cada um com sete perguntas, dentre elas objetivas e discursivas. As objetivas obedeceram a uma escala de muito satisfeito, satisfeito, pouco satisfeito e insatisfeito, todas elas respondidas entre os alunos. Entre os professores, sete questionários com nove perguntas objetivas e discursivas, onde as objetivas correspondiam à escala das questões objetivas do questionário descrito acima e foram respondidos. Os questionários foram aplicados no último dia das oficinas e, com encerramento das atividades, foram analisados utilizando um programa de planilha eletrônica para contabilizar em porcentagem os dados obtidos. Após as análises dos dados houve um encontro com os professores ministrantes das oficinas foram apresentados e discutidos uma previa dos dados analisados. Aos alunos foi solicitado, que formassem grupos, e cada grupo fizesse um trabalho para a disciplina de biologia celular, aplicando uma modalidade estudada na oficina. Esses alunos foram divididos em 4 grupos e para cada grupo foi sorteado uma modalidade, após duas semanas esses trabalhos foram apresentados na disciplina de Biologia Celular.

\section{RESULTADOS E DISCUSSÃO}

Após a análise das respostas dos questionários dos alunos participantes foi possível conhecer melhor o público participante da oficina. Dos participantes, $79 \%$ dos estudantes são graduandos do primeiro semestre de Licenciatura em Ciências Biológicas - enquanto outros $21 \%$ estão divididos entre o $5^{\circ}$ e o $10^{\circ}$ semestre do mesmo curso. Por sua vez, quando avaliados com a pergunta "Você já teve algum contato com diferentes aulas de biologia celular? Quando e onde foi? Comente brevemente esta experiência”, 69\% dos alunos responderam que "não" tiveram contato com metodologias diferentes, já outros 31\% responderam que "sim”. Dentre os que obtiveram contato, afirmaram que as atividades foram desenvolvidas com eles em sala de aula no ensino médio com vídeos e jogos. Outros responderam que já presenciaram essa forma de metodologia em curso ministrados por grupos dentro da graduação ou até já ministraram cursos que utilizavam alternativas diferentes. Dentre as falas, destacamos algumas abaixo: 
“Apenas nas oficinas do PET Biologia, antes disso não haveria tido nenhum contato. Foi uma experiência fantástica, pois mostrou que a biologia pode ser algo ensinado de maneira divertida e fácil de aprender” (Aluno 2).

Figura 1. Níveis de Satisfação dentre as quatro oficinas de acordo com os alunos

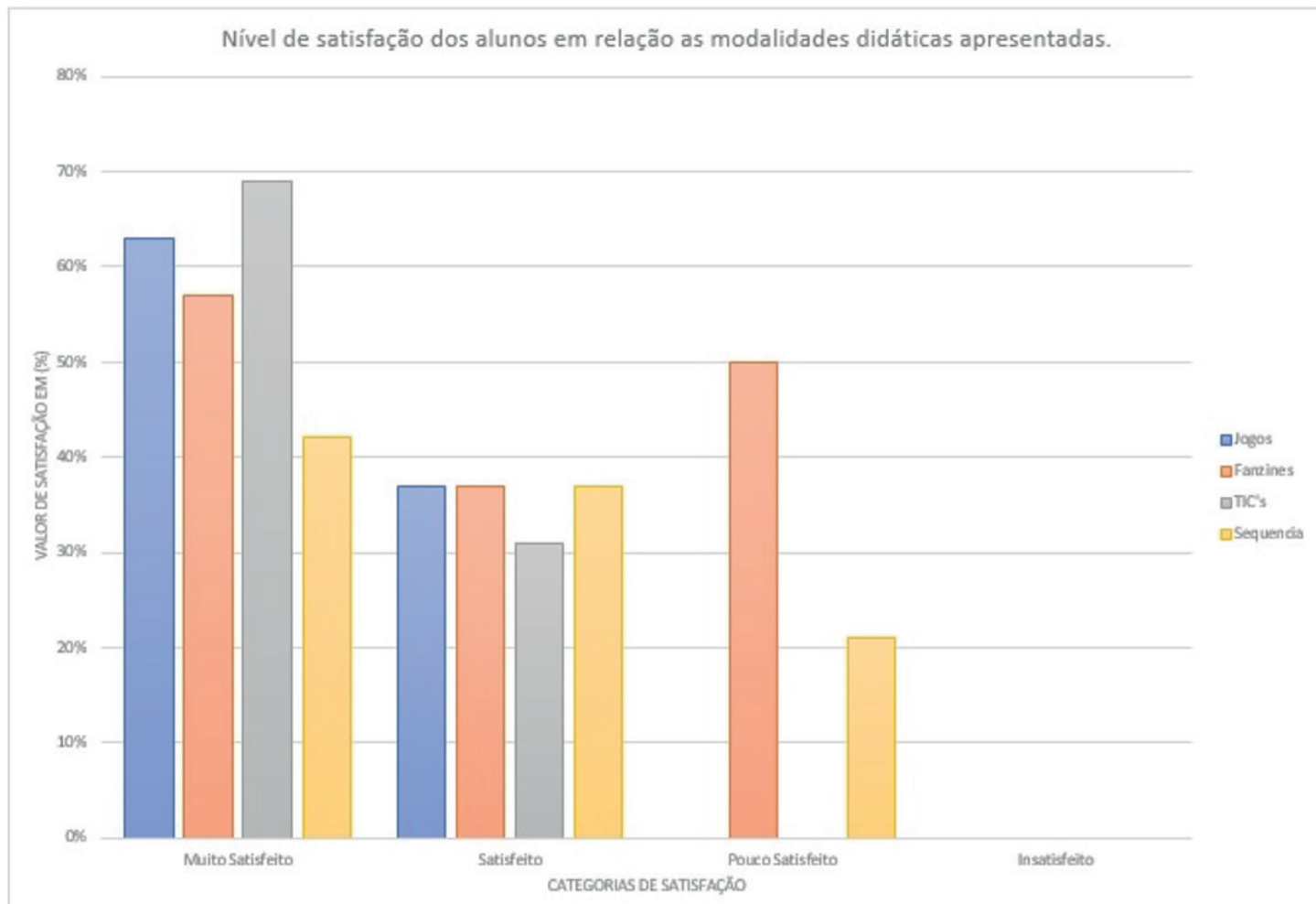

Fonte: próprio autor

Quando avaliados os níveis de satisfação dentre as quatro oficinas (Figura 1), a oficina de TIC’s teve maior nível de satisfação, classificada com 69\% de "muito satisfeito" e 31 \% de "satisfeito pelos alunos". Em seguida, a oficina de jogos com 63\% de "muito satisfeito" e 37\% de "satisfeito" e a oficina de fanzines com 57\% de estudantes "muito satisfeitos" e 37\% de "satisfeitos" e 5\% "pouco satisfeitos". Logo após a oficina de sequências didática com $42 \%$ de "muito satisfeito", 37\% de "satisfeito" e 21\% "pouco satisfeito". A avaliação dos estudantes em relação a metodologia utilizada em toda a oficina também foi positiva já que $79 \%$ dos alunos se mostraram muito satisfeitos com a metodologia em geral enquanto $21 \%$ se demonstraram satisfeitos. Já em relação ao material didático apresentado durante a oficina $90 \%$ alegaram terem ficado "muito satisfeitos" e $10 \%$ deles "satisfeitos".

Quando perguntamos aos estudantes de licenciatura e futuros professores se "Você utilizaria nas suas aulas, esse tipo de metodologia? Por quê?”, obtivemos $100 \%$ de respostas positivas quanto ao uso destas estratégias. As justificativas podem ser exemplificadas com as falas de alguns alunos descritas logo abaixo:

“Porque facilita a compreensão e torna a aula atraente e menos cansativa” (Aluno 3);

"Por que hoje em dia as salas de aula precisam ser ambientes inovadores para cativar o pleno interesse dos alunos” (Aluno 4);

Na última pergunta foi indagado quais seriam os pontos positivos e negativos da oficina como um todo. Em relação a pontos negativos afirmaram que a oficina foi realizada em pouco tempo, ressaltando principalmente aquele destinado a realização das atividades propostas. Já entre os pontos positivos destaca-se a boa didática 
dos professores ministrantes e a dinâmica e interdisciplinaridade presentes na oficina, que se repetiram em 90\% dos questionários. Além disso, também apareceram pontos como “criatividade” e "socialização" apontados com frequência em torno de $30 \%$.

Já a análise dos professores ministrantes demonstrou que todos além de serem formados em Licenciatura em Ciências Biológicas possuíam, em sua maioria (aproximadamente 60\%), mais de 14 anos de formação. Além disso, o grupo era unicamente composto por professores do ensino público, atuando principalmente no ensino médio. Quando perguntados sobre "Quais as dificuldades encontradas para explicar os assuntos de biologia celular?”, 90\% responderam que a principal dificuldade dos professores para transmitir o conteúdo para seus alunos seria pelo conteúdo ser considerado muito abstrato, corroborando com as dificuldades citadas por Randi e Carvalho (2013). Dentre as falas destacamos:

"Transformar a abstração em algo concreto para que os alunos fizessem uma comparação para facilitar o aprendizado sem comprometer o conteúdo" (Professor 1).

"Por serem assuntos complexos e abstratos torna-se difícil a compreensão dos alunos desse modo a dificuldade maior é encontrar a melhor forma de ser compreendido por eles” (Professor 2).

Também podemos lembrar que a abstração, citada anteriormente, também pode ser relacionada com a necessidade de uma "infraestrutura de laboratório, com microscópios e aparelhagem que possibilitem a observação e estudo desses aspectos” (ORLANDO et al., 2009, p. 2). As carências desses objetos, por muitas vezes, diminuem as possibilidades as serem utilizadas pelo professor no processo de ensino-aprendizagem destes conhecimentos. Na próxima pergunta, os docentes foram questionados se algum deles já havia utilizado alguma estratégia didática para solucionar dificuldades e, se na ocasião obteve êxito? Entre respostas, 85\% responderam que já utilizaram estratégias para facilitar a transmissão do conteúdo por seus alunos, "Aula digital simulando técnicas de microscopia e aulas práticas com materiais alternativos (Professor 4)”.

Na questão no qual foi analisado o grau de satisfação ao ministrar a oficina, 85\% responderam que estavam "muito satisfeitos" enquanto outros $15 \%$ se disseram "satisfeitos". Já quando avaliado o aproveitamento dos alunos na oficina, 80\% responderam "muito satisfeitos" e 20\% "satisfeitos". Por fim, os docentes foram perguntados "qual a contribuição [da oficina] para seu cotidiano docente?”. Os pontos mais comentados foram a oportunidade de compartilhar as vivências, metodologias novas, troca de experiências entre os participantes e a contribuição na formação de novos professores. Dentre as frases que exemplificam as respostas podemos citamos:

\footnotetext{
"Poder compartilhar minhas vivencias em sala de aula e poder repensar na minha didática" (Pro-
} fessor 3);

“Ter a oportunidade de fomentar a riqueza e beleza da formação docente a fim de incentivar futuros professores” (Professora 7);

Aos participantes da oficina que eram alunos do primeiro semestre do curso de ciências biológica que fazem a disciplina de Biologia da Célula, foi solicitado aos grupos que desenvolvesses trabalhos (Figura. 2) relacionados as estratégias didáticas aplicada na oficina e obtivemos quatro trabalhos um jogo, fanzine, sequência didática e aulas com auxílio de vídeos. 
Figura 2. Estratégias didáticas desenvolvidas pelos participantes da oficina. A) Jogo tabuleiro RNA; B) Fanzine secreção proteica; C) Sequências didática via metabólica.
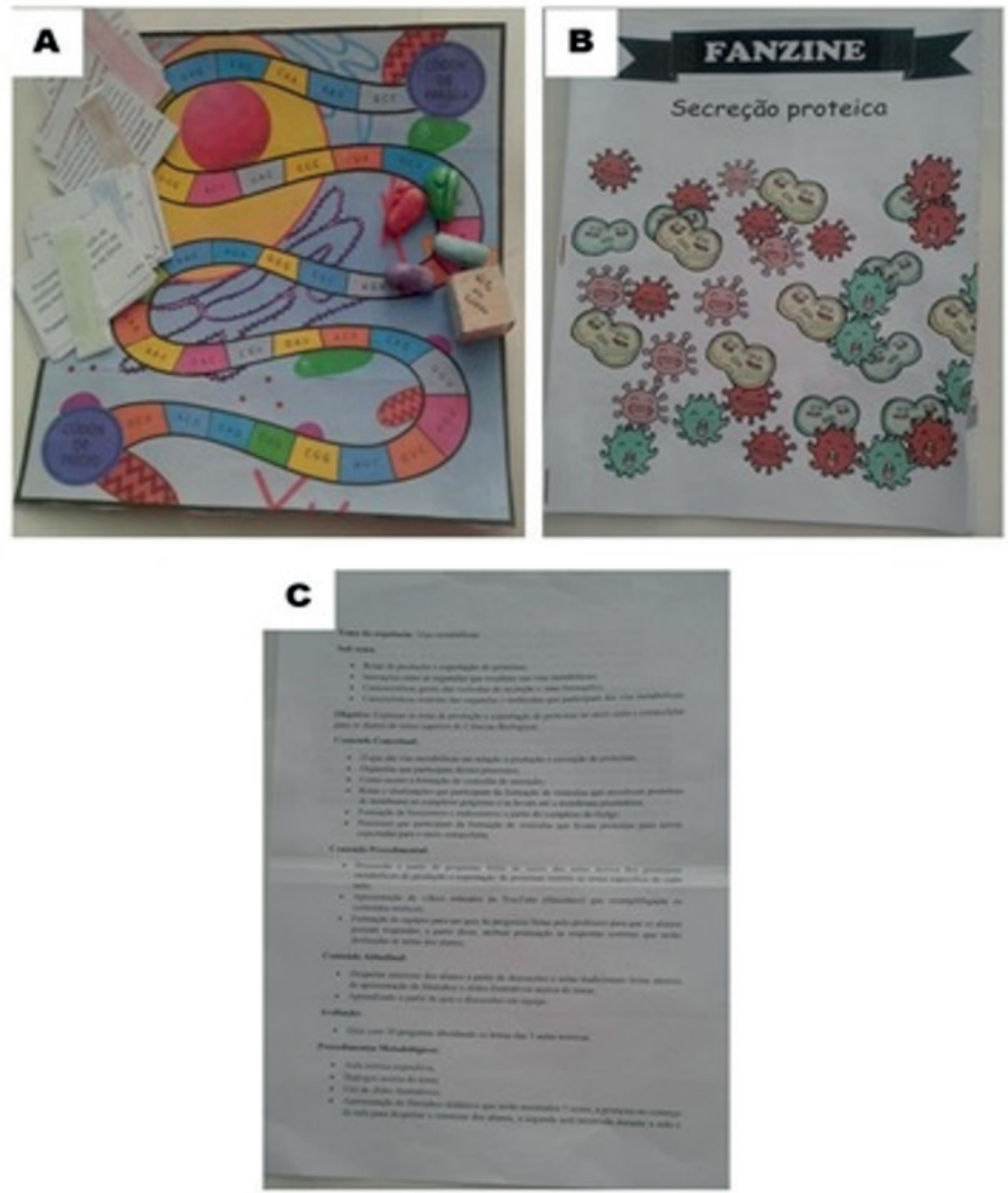

Fonte: próprio autor

O jogo (Figura 2A) desenvolvido foi tabuleiro que seu objetivo é traduzir a mensagem genética e formar uma proteína chegando ao códon de parada, era composto por um tabuleiro que apresentava um caminho de casas que seriam os códons e a cada lançamento de um dado onde apresentava as seguintes opções perguntas fáceis , medias e difíceis como também pule uma vez, volte um códon e carta coringa, cada jogador teria 30 segundos para responder a pergunta e 2 chances de respostas para questões abertas e 1 para questões de múltipla escolha a medida que acerta as respostas, a quantidade de ATP’s que se ganha é a quantidade de códons anda. Indagado os desenvolvedores do jogo de como seria utilizada em sala de aula? Este jogo seria uma complementação de aula teórica podendo ser utilizado em aula de revisão para fixação do conteúdo ministrado anteriormente. 
Fanzines (Figura 2B) com tema de secreção proteica onde foi desenvolvido a partir de que organela realiza, qual a função, o que significa, como é o processo de realização da secreção proteica, os desenvolvedores do fanzine pretendem a sua utilização como um material de apoio podendo ser utilizado como atividade extraclasse.

Sobre as TIC”s desenvolveram uma aula expositiva complementada por uma seleção de vídeos que ajudaria os alunos na compreensão e fixação do conteúdo como também na melhor visualização de estruturas microscópicas que compõem o processo que foi estudado nos vídeos facilitando a melhor visualização dessas estruturas pelos alunos.

A sequência didática (Figura 2C) foi desenvolvida com tema vias metabólicas tem por objetivo explanar as rotas de produção e exportação de proteínas no meio intra e extracelular para alunos de curso superior de ciências biológicas, compõem 4 aulas de 2 horas cada onde no processo metodológico estão aula teórica expositiva, diálogos acerca do tema, uso de slides ilustrativos, apresentação de filmes didáticos e um quiz que serviria de avaliação. Uma sequência bem elaborada seguindo todos os passos fundamentais para a facilitação da explanação de um conteúdo que apresenta uma complexidade.

Os grupos foram questionados sobre a importância da inclusão total ou parcial de novas estratégias de ensino nas aulas convencionais podendo ser nível fundamental, médio ou superior, os alunos demonstram que como futuros professores de biologia utilizariam essas novas estratégias no planejamento de suas aulas afim de facilitar a compreensão de conteúdos complexos pelos seus futuros alunos.

\section{CONSIDERAÇÕES FINAIS}

Com base nos resultados, pode-se perceber que a experiência proporcionada pela oficina, principalmente no que se refere a apresentação das diferentes estratégias para o ensino de biologia celular foi positiva. Ficou evidente que, tanto entre os professores ministrantes e os alunos participantes, o ensino de assuntos relacionados ao estudo da célula pode ser facilitado quando apresentado através de uma estratégia ou modalidade didática adequada aplicada. Nesta perspectiva recomenda-se, principalmente em espaços de formação de professores, a realização e o estabelecimento de discussões que tenham como o objetivo a divulgação de tais temáticas. Além disso, ressalta-se o potencial presente na integração entre alunos de pós-graduação/professores de escolas públicas e os licenciados em Ciências Biológicas como um espaço de troca de experiências e oportunidade para apresentar e conhecer outras metodologias.

\section{REFERÊNCIAS}

ALMENARA, J. C. Nuevas Tecnologias, comunicacion y educacion. EDUTEC. Revista Electrónica de Tecnologia Educativa. 1996. Disponível em:<http://www.edutec.es/revista/index.php/edutec-e/article/ view/576>. Acesso em: 12 out. 2017.

ANDRADE, S. S; SENNA, N. C. Fanzines na sala de aula: Expressividade e Autoralidade. In: SIMPÓSIO 5 - COMPARTILHAMENTOS DO ENSINO DA ARTE: CONEXÕES INTERATIVAS COM REALIDADE COTIDIANA, 24., 2015, Pelotas. 24º Encontro da ANPAP. Pelotas: Anpap, 2015. p. 2880 - 2896.

BORGES, R. M. R.; LIMA, V. M. R. Tendências contemporâneas do ensino de Biologia no Brasil. Revista Electrónica de Enseñanza de Las Ciencias, Vigo, v. 1, n. 6, p.165-175, jul. 2007.

BUENO, A. de P. La construcción del conocimiento científico y los contenidos de ciencias. In: ALEIXANDRE, M. P. J. (Coord.) Enseñar ciencias. Barcelona: Editorial GRAÓ, p. 33-54, 2003. 
FIALHO, N. N. Jogos no Ensino de Química e Biologia. Curitiba: IBPEX, 2007. Disponível em>. Disponível em:<http://www.edutec.es/revista/index.php/edutec-e/article/view/576>. Acesso em: 12 out. 2017.

FIALHO, N. N. Os jogos pedagógicos como ferramentas de ensino. In: IBPEX, Não use números Romanos ou letras, use somente números Arábicos., 2007, Curitiba. Anais IBPEX. Curitiba: Organização do Evento, 2007. p. 12299 - 12306.

KRASILCHIK, M. Prática de Ensino de Biologia, 4. ed., São Paulo: Editora da Universidade de São Paulo, 2011, 199 p.

KRASILCHIK, M. (1987). O professor e o currículo das ciências. São Paulo: Universidade de São Paulo.

ORLANDO, T. C.; LIMA, A. R.; SILVA, A. M.; FUZISSAKI, C. N.; RAMOS, C. L.; MACHADO, D.; FERNANDES, F. F.; LORENZI, J. C. L.; LIMA, M. A.; GARDIM, S.; BARBOSA, V. C.; TRÉZ, T. A. Planejamento, montagem e aplicação de modelos didáticos para abordagem de biologia celular e molecular no ensino médio por graduandos de ciências biológicas. Revista Brasileira de Ensino de Bioquímica e Biologia Molecular, Alfenas, n. 1, p. 324-340, set. 2009.

MOYLES, J. R. Só brincar? O papel do brincar na educação infantil. Tradução: Maria Adriana Veronese. Porto Alegre: Artmed, 2002.

RANDI, M. A. F.; CARVALHO, H. F. Aprendizagem através de role-playing games: uma abordagem para a educação ativa. Revista Brasileira de Educação Médica, Rio de Janeiro, v. 37, n. 1, p. 80-88, 2013.

REZENDE, F. As novas tecnologias na prática pedagógica sob a perspectiva construtivista. Ensaio Pesquisa em Educação em Ciências, v. 2, n. 1, p. 75-98, 2008.

SARMIERI, V. S; JUSTINA, L. A. Fatores inibidores da atividade pedagógica. In: Encontro Nacional de Didática e Prática de Ensino, Curitiba, n. 12, p. 87- 94, 2004.

SOUZA, J. W. A; ESCARPINETE, L. M; ASSIS M.C; MELO, F. B. M. O papel do aluno de letras como professor de língua materna no ensino médio: os desafios do Pibid. In: xii encontro de extensão, Não use números Romanos ou letras, use somente números Arábicos., 2016, Paraiba. Anais XII Encontro de Extensão UFPB. Paraiba: Organizadores do Evento, 2016. p. 20 - 28. 